Rabaska

Revue d'ethnologie de l'Amérique française

\title{
Ceinture fléchée : son origine québécoise éclipsée par la Banque du Canada
}

\section{Monique Genest-LeBlanc}

Volume 15, 2017

URI : https://id.erudit.org/iderudit/1041129ar

DOI : https://doi.org/10.7202/1041129ar

Aller au sommaire du numéro

Éditeur(s)

Société québécoise d'ethnologie

ISSN

1703-7433 (imprimé)

1916-7350 (numérique)

Découvrir la revue

Citer ce document

Genest-LeBlanc, M. (2017). Ceinture fléchée : son origine québécoise éclipsée par la Banque du Canada. Rabaska, 15, 196-198.

https://doi.org/10.7202/1041129ar d'utilisation que vous pouvez consulter en ligne.

https://apropos.erudit.org/fr/usagers/politique-dutilisation/ 


\title{
Opinion
}

\section{Ceinture fléchée : son origine québécoise éclipsée par la Banque du Canada}

\author{
Monique Genest-LeBlanc
}

Monsieur le Premier Ministre ${ }^{1}$

La présente veut corriger une erreur historique concernant l'origine et la description de la ceinture fléchée apparaissant sur le recto du nouveau billet de 10 dollars canadien. En effet, on peut lire l'interprétation suivante sur le site de la Banque du Canada :

\section{Ceinture fléchée.}

Ce motif reproduit l'aspect caractéristique de la ceinture fléchée (aussi appelée " ceinture de l'Assomption »), qui est un important symbole culturel des Métis. La ceinture fléchée revêt aussi de l'importance dans la culture canadiennefrançaise. Portée par les habitants, elle est devenue une marque particulière aux voyageurs et aux commerçants de fourrures au cours du XVIII siècle. $^{2}$

Je suis fort étonnée que la Banque du Canada ait, par erreur ou ignorance, présenté la ceinture fléchée dite de L'Assomption comme symbole des Métis, sans faire allusion à son origine québécoise. Je considère malheureusement qu'il s'agit d'une information historique erronée en raison du peu d'intérêt qu'on accorde de nos jours à cet élément de notre patrimoine culturel pourtant confirmé par l'histoire. Il faut se rappeler que ce sont nos ancêtres québécois qui, selon des attestations remontant à 1776, ont créé une ceinture dont le motif a évolué jusqu'à la ceinture de L'Assomption. La citer comme une banale coïncidence, subordonnée à la ceinture métisse n'est pas juste. C'est lorsque les habitants du Bas-Canada, engagés par la Compagnie du Nord-Ouest, sont partis dans les Pays d'en haut portant leur ceinture que cette ceinture a suscité un désir chez les autochtones d'en posséder une semblable. On verra donc des commandes de laine peignée (worsted) venir d'Angleterre pour cette

1. Outre Justin Trudeau, Premier Ministre du Canada, cette lettre a aussi été adressée à la Banque du Canada et à Mélanie Joly, Ministre du Patrimoine canadien.

2. Source : www.banqueducanada.ca/billets/billet150 (consultée le 8 juillet 2017). 
compagnie qui fera confectionner des ceintures par leurs travailleurs (working people). Ces ceintures de différentes dimensions seront ensuite acheminées vers les postes de traite de la Cie du Nord-Ouest tels que nous le révèlent les archives : par exemple lac Nipigon, Grande-Rivière, lac Seul, lac La Pluie et lac des Bois en Ontario ; Rivière-aux-rats, York Factory, Norway House et Oxford House au Manitoba ; lac La Ronge en Saskatchewan; ou White Fish Lake et lac des Esclaves en Alberta.

Ainsi, entre 1806 et 1858, on a vendu des ceintures à des Amérindiens et à des Métis dont on a conservé le nom : au lac La Ronge, à Thlough elder, The Boiteux $3^{\text {rd }}$ son ; au lac La Pluie, à Kinnotochary, à Taioraniagarere, et à Joseph Picard ; à un Indien Peninsis ; aux Métis Jos. Guimont, Joseph Primeau et Jos. Jourdin, ainsi qu'à Lagaki ; puis aux Amérindiens Piabewash, Cavitash, Maidootug, Maitapu, etc.

Heureusement, entre 1778 et 1780, des Allemands présents au BasCanada ont laissé des témoignages écrits dans leur journal personnel, ont fait des croquis et des dessins du paysan portant sa ceinture. Merci à ce soldat anonyme logé chez l'habitant à Sainte-Anne-de-la-Pérade, merci à Madame de Riedesel, merci à F.V. Germann et merci à ce Bavarois forestier à Québec qui nous ont laissé ces traces irréfutables.

Il y a quelques années, quand on a créé la journée des Amérindiens le 21 juin, on a mis la ceinture de L'Assomption sur une affiche comme étant leur propriété exclusive. J'ai écrit alors au Ministre Roméo LeBlanc pour lui signaler que la ceinture de L'Assomption était tout simplement québécoise, alors que la magnifique ceinture wampoum, elle, était bien d'origine amérindienne.

Pour votre information, j'ai fait des recherches très poussées sur l'histoire de la ceinture fléchée québécoise. J'ai fait mon mémoire de maîtrise ainsi que ma thèse de doctorat sur la ceinture fléchée à l'Université Laval sous la direction du regretté Jean-Claude Dupont. Mes recherches sont référencées et tirées de documents authentiques de par le monde ${ }^{3}$. C'est donc sur ses bases que je me permets de défendre la valeur de la ceinture fléchée et la place qu'elle a occupée et continue d'occuper en continuant mes recherches, la pratique du tissage et l'enseignement que je dispense depuis 48 ans. J'espère que vous pourrez redonner au Québec ce qui appartient en toute justice au Québec, et pourrez corriger toute documentation qui ne serait pas conforme à notre histoire nationale.

À cette fin, vous trouverez ci-dessous le texte que je propose en remplacement de celui qui figure dans le site de la Banque du Canada :

3. Monique Genest-LeBlanc, «Une jolie cinture à flesche ». Sa présence au Bas-Canada, son cheminement vers l'Ouest, son introduction chez les Amérindiens, Québec, Les Presses de l'Université Laval, «Ethnologie de l’Amérique française », 2003. 
Ceinture fléchée.

Ce motif reproduit l'aspect caractéristique de la ceinture fléchée, aussi appelée « ceinture de L'Assomption ». Créée sur le territoire actuel du Québec vers la fin du Régime français, elle a d'abord été portée par les habitants et est devenue une marque particulière aux voyageurs et aux commerçants de fourrures au cours du XVIII ${ }^{\mathrm{e}}$ siècle. Par la suite, elle a été adoptée par les Métis qui la considèrent comme un symbole culturel important.

Veuillez recevoir, Monsieur le Premier Ministre, l'expression de mes meilleurs sentiments.

Respectueusement vôtre,

Monique Genest-LeBlanc, Ph.D. Ethnologue et artisane de la ceinture fléchée Brossard (Québec) 